\title{
English Lexical Enrichment: Methods and their Frequency/Productivity in 1785, 1885, and 1985
}

\author{
Rozgar Y Omar ${ }^{1}$, Nechirvan Hassan Jawzal ${ }^{2}$ \\ ${ }^{1}$ Department of Mathematics, College of Science, Salahaddin University-Erbil \\ 2Department of English Language, Faculty of Humanities, University of Zakho
}

\begin{abstract}
There are a number of different categories of enriching English vocabulary, which are grouped into smaller methods based on the way they function. Some methods are productive, while some others are creative. Besides, some methods are more or less frequent/productive than others which may be due to a number of reasons such as the nature of the language itself and possibly the period the language is undergone on. Therefore, three different years from different centuries, precisely 1785, 1885, and 1985, are taken from Oxford English Dictionary (OED) to discover the frequency/productivity of the methods in each. The concrete results show that the language and time play a role in the frequency and productivity of each method. They also indicate that the frequency of some methods has gradually increased while of some others decreased.
\end{abstract}

Keywords: lexical enrichment, word-formation, frequency, productivity, OED.

\section{Introduction}

There are different reasons and distinctive ways to enrich English vocabulary. According to Minkova and Stockwell (2009: 5-22), there are two main concepts of making new word meaning and neologism, namely regular word-formation and new word-creation. The first one is productive while the second is creative.

Regular word-formation includes the processes of attaching affixes to a base or a stem (affixation), converting the syntactic category of a word without changing its form (conversion), and connecting words/combining forms (compounding). The second process, on the other hand, which is new wordcreation, is recognizable by its individual usage. It encompasses different procedures of generating new words such as creation de novo, blending, clipping, back-formation, abbreviation, eponymy, and other sources like onomatopoeia and reduplication.

Two other methods of vocabulary enrichment, which is termed 'foreign' because of the way they look to the native language, are borrowing and folk-etymology. Borrowing is the process in which a language, instead of assisting from its lexicon, loans vocabulary from another language (Katamba, 1994:133) without a major change, while, folk-etymology is a false assumption of a form (Ratih and Gusdian 2018: 27) and modeling it "under the influence of some other word" (McAtee, 1951: 90).

Bauer (2001) examines different methods to find an answer for whether a process of coining a new word is productive or creative. Then he finally concludes that it is very problematic to distinguish between productivity and creativity.

Nonetheless, instead of arguing to respond to his claim, in this work, the theory of Minkova and Stockwell is taken into account that some processes can be productive and some others can be creative. So, although there are different methods of lexical enrichment in English and many studies have been conducted about it (Plag 2018, Štekauer and Lieber 2006, Bauer 1983, Kiparsky 1982), the objective is to examine three different years from different centuries to discover which processes appear to be more or less frequent/productive. In other words, the aim of this work is to find whether centuries can play the key role in having the lexical enrichment categories being more 
or less frequent. The significance of the research lies in the data collected to determine that centuries can affect the frequency/productivity of the categories. Due to the word limit and the size of the current research, this research couldn't cover the data from the three centuries as a whole as it would require years of academic research.

The online Oxford English Dictionary (OED) will be used to find the data. Then the results in the light of a possible discussion will be coped with. It must be stated, though, that the entities found on OED at a specific time does not mean that the word is created just then. To a word to entre in a dictionary, it goes into a language change process until it will be recorded as an entity in that dictionary. Language starts to change once an individual or a group of individuals create a neologism (i.e. a first-time new word occurrence) which by time is adopted by more speakers than by a community, and then it is finally accepted as a standard usage by the public (McMahon, 1994:8-9). So the words found in our data might have been created sooner than the OED shows, but, because there cannot be any record to trace, the entities we find will be considered as first time used/created.

\section{Literature Review}

As discussed above, there are different methods of lexical enrichment such as regular word-formation, new word-creation, and foreign enrichment. Each is dealt with separately in this section.

The first category of regular word-formation is affixation. It is a process to produce a new word by adding a listeme (prefix, suffix, interfix or infix) to an existing lexeme (stem/root/base). Due to their rareness and restriction, neither interfix nor infix will be studied here.

A prefix is an affix attached to the beginning of a lexeme (Tokar, 2012: 56). Semantically, prefixes can be categorised into different groups (Plag, 2018: 98) such as (a) quantifying prefixes as uni-, which quantifies the meaning of the lexeme and expresses 'one' in unicolour, (b) negation prefixes as in- in infertile, (c) locational prefixes as inter-in interstation, (d) temporal prefixes as pre- in prehistoric, (e) prefixes of degree as sub- in substation, and (f) reversative/privative prefixes as dein deaerate (Montero-Fleta, 2013: 273).

Also, suffixes, attached to the end of an element, can be classified into different groups such as (a) nominal suffixes, where they will be added to root/stem and the syntactic category, if it is not already a nominal, will change into a nominal phrase, such nominal suffixes are -ance in acceptance, -ee in employee, -hood in falsehood. Other categories of suffixes are (b) verbal suffixes which derive verbs mostly from nouns and adjectives, such as -fy in beautify and -ise in familiarise; and (c) adjectival suffixes -able in employable and -ive in active. The last group is called (d) adverbial suffixes as in -ly in quickly and -ward in homeward.

The second category is conversion, which is a method of converting a word class of a word into another. For instance, the meaning of to father is derived from the noun a father (Harley, 2006:105). Sometimes it is also called 'zero derivation' because the shape and the form of the 'input word' will not be altered. According to Katamba (1994: 48-49), there is one possible approach to distinguish what syntactic category converted words are which is only by the grammatical context they are in

The last method of regular word-formation is compounding. A compound is the combination of more than one free morpheme (words/combining forms) sharing a conceptual relation.

On the other hand, the second category of lexical enrichment is new word-creation. It is subcategorised into different methods.

Creation de novo is a process of introducing a new word which happens unexpectedly, rarely to create a word totally from scratch. The process is sometimes 
called word-manufacture (Bauer, 2006: 498) because often they appear as trade-marks, such words are Exxon, dongle, and Kodak.

Blending refers to creating a new lexeme by clipping two different words then blending them to stand as one morpheme, often by clipping the last letters of the first morpheme and clipping the first parts of the second, where Kelly (1998: 579) believes components "fall at major phonological joints". Chillax (chill + relax), infomercial (information + commercial), chortle (chuckle + snort) are examples of blending.

Clipping is another creative process of coining a word by clipping off or shortening an existing, usually multisyllabic, word. Possibly, due to its length and difficulty of pronunciation, speakers clip common words (Harley, 2006: 95), like gymnasium to gym, Internet to net, vegetarian to vegan, and jammies from pyjamas.

Another way of creatively introducing new words is back-formation. It is a process when a "presumed affix" (usually a suffix) is clipped off from an existing word. For instance, the word sedate is derived from the word sedative (Brinton, 2000: 98). It came to use when the speaker considered the recognizable -ive at the end of the word is transparent. Other examples of backformation can be seen in televise (from television), orate (from oration) and burgle (from burglar).

Another shortening mode of making new words is abbreviation. This is a process, whereby a long compound is clipped off to one word, to take the initial sound of words and combine them into one element (Grange and Bloom, 2000: 2). It is phonologically subcategorised into two types, namely acronyms and initialisms (or alphabetism). The difference between both is when the set is pronounced as a single component it is an acronym as gif (graphic interchange format) pronounced as /gif/ (or/dzif/). Yet, the abbreviated KRG word is an example of initialisms because each letter of KRG, which stands for 'Kurdistan
Regional Government', is pronounced individually, / keI a:r dzi:/.

Eponymy, which is a creative process of making new words, is based on the derivation of names. A great number of discoverers in medicine, biology and physics are examples of eponymy (Minkova and Stockwell, 2009: 19). It can be classified into different groups according to personal names (quisling, from Vidkun Quisling), geographical names (jean, from Italian city Genoa), mythical characters (gorgon, from Greek Mythology), and commercial brand names (Netflix as in "Let's Netflix and chill").

Other methods of new word-creation, dependant on the pronunciation of the lexeme, are onomatopoeia (or echoing/imitative) and reduplication. Onomatopoeic words are those words that for listeners can be readily understandable from the sound of the word, as crack, vroom, his, and beep, where these sound like a noise. Reduplication, also based on the pronunciation of the word, is a process to make a compound noun by repeating a word or part of a word (Nadarajan, 2006: 39), and based on juxtaposition, it can be classified into two categories: (a) Full: night-night, ack-ack, and gee-gee, and (b) Part: tell-tale, funny-bunny, on-off, eff-off, mucktub, slip-slop, even-steven, and man-o-man (Rastall, 2004: $40)$.

Lastly, the foreign methods of lexical enrichment are borrowing and folk-etymology. A language borrows a word from another for different reasons, such as culture (coffee), politics (parliament), religion (hajj), economy (market), and prestige (beef). As defined above, folk-etymology is a replacement of another form, and can happen on two levels: functional (wordformation change) and lexical change (in terms of phonetics/semantics) (Coleman and Kay, 2000: 22, Michel, 2015: 1) such as cockroach, bridegroom, bus, -gate, and mayday (Moore, 2014: 18-20). 


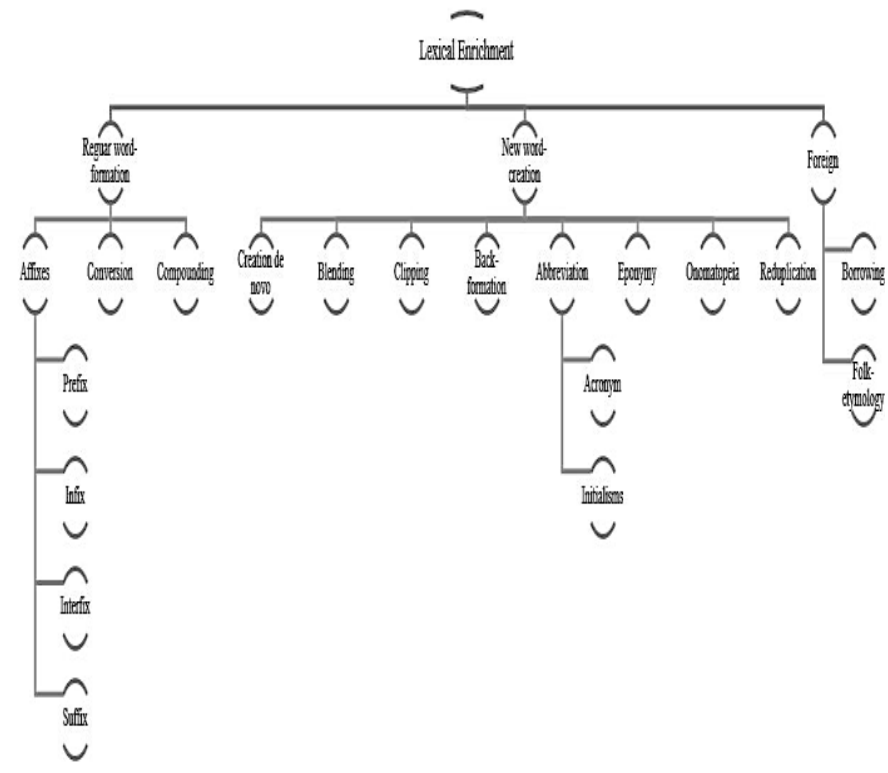

Figure 1: lexical enrichment methods in English

\section{Methodology}

As shown above, there are different processes of lexical enrichment in English. Some are more productive and more frequently used, whereas some others are rarely used. Also, a large number of studies in this field have been conducted such as in Cutler (1980), Štekauer (1998), Dressler and Ladányi (2000), Bauer (2001), Plag (2006), Fernández-Domínguez (2010), and Hacken and Panocová (2013). However, few of them concentrated on frequency/productivity of each process in a certain period comparing to another period. Therefore, this study will compare each category in three different periods of time specifically 1785,1885 , and 1985 so as to determine which method is overall frequent/productive. These specific years, without any linguistic significance, are selected randomly from different centuries because taking data from each century as a whole would need years of work and cannot fit into a research study due to word limit. The main idea here is to find how English enriched its vocabulary in different centuries, at particular points. Our data are from the online OED (Oxford English Dictionary) which is described as a 'giant source' (Good, 2012). The process of collecting data primarily started by Advanced Searching of words coined in
1785, 1885, and 1985.

\section{Results and Discussion}

According to the collected data, 370 words have enriched English vocabulary in 1785, 953 in 1885, and 187 in 1985. However, some of the words in each period ( 34 in 1785, 148 in 1885, and 26 in 1985) were not counted into the data for different reasons which are discussed below.

a) Unknown/ uncertain origin: bawd, donkey, fuji, natty, olivart, and tosher.

b) Variant/alteration/obsolete form: caneva, geezer, hackit, knobble, pisette, and squitch.

c) Change in meaning: buzz (as another verb with different semantic meaning), ducker, nickle, and sledger. d) Mixed methods: buckminsterfullerene (eponym + suffix), conceptualist (concept + ualist or directly from the French conceptualiste), interhyal (inter- + hy(hyoid) + -al), and nanny (nan + y or Nanny pet form names for Anne/Agnes).

e) Unclear method: autogravure (OED states that it is a loan word from French combined with an English element, though auto- and gravure had been used in 1876 and photogravure in 1873. Therefore, it is either compound word or a blended one), Brown Bess (even though OED states that it is a compound of Brown (adjective) + female name Bess, Grose (1931: 54) gives an explanation and says it is "more probably a personal name"), barrack (OED is not certain whether it is originally from Australian (alteration of borak) or an entity from English Dialectical Dictionary which refers to the word as northern Irish (Wright 1898: 171), plus there has been barrack in 1686 with different meaning. Though, still, the method through which this word is formed is not determined), Locomobility (OED states that it is a compound from loco- + mobility, while first use of loco is registered in 1786, which means the word is not formed by compounding. Also, the words locomotive and locomotion appeared first in 1612 and 
1646 respectively. Therefore, it can be either blending or borrowing from French locomobilite (appeared in 1777)), pitmatic (OED says it is a compound word, but it is derived from pit + -matic (of mathematic) and there has been pitmatics in 1844 , so it is either blending or back-formation), and spatch-cock (OED suggests that it is an "abbreviation of a dispatch cock, while it has been stated by Palmer (1882: 366) that the word came from "spicthcock". In Sayers (2012: 4-5), it is claimed that the origin of the word is still unclear). Hence, the above mentioned entities are not counted in our data.

Relevant to OED's etymology, dozens of entities are not categorised or are miscategorised into different enrichment methods, such as chug, corella, electret, Mesmerite, pulvinarian, and skatepunk. OED claims chug (v.) is an onomatopoeia but it is conversion from chug (n.) used in 1866. For corella, OED does not give any information about its etymology, while Merriam Webster Online states it is a "native name in Australia", which makes it eponym. However, Dixon et al. (2006: 83) state that it is a borrowed word from Wiradhuri, probably from garila. Based on OED, electret is a compound and it is formed from electr- (in electric) + -et (in magnet); hence it is a blend. Mesmerite is claimed by OED to belong to double-formation (a proper name Mesmer combined with -ite (eponymy + suffix)). However, it would be true if mesmerism was not formed in 1784. Therefore, mesmerite can be observed as a base + suffix, which is counted as suffixation. Pulvinarian is suggested to be a loan in OED while its base, pulvinar, was first used in 1599, so it is formed through suffixation. For skatepunk, OED says it is a compound word, but it is a blend, not from skate + punk but skate(board) + punk. Thus, all the data are calculated and categorised based on, not OED's etymology but, our knowledge to lexical enrichment. In 1785, 336 entities have been included. As Table 1 illustrates, in total, borrowing appeared to be the most frequent method with 114 words (33.9\%). The words are borrowed from these languages: Afrikaans (skoff), Arabic-Persian (burkundaz), Cree (wapacuthu), Dutch (veld), French (spicule), German (muggent), Hindi (zillah), Italian (studio), Latin (cembra), and Sanskrit (yoga).

Table 1: methods of lexical enrichment in English in 1785, by number and in percentage

\begin{tabular}{|c|c|c|c|c|c|c|c|c|c|c|c|c|c|c|}
\hline 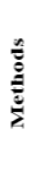 & $\begin{array}{l}\stackrel{0}{G} \\
\text { 总 }\end{array}$ & $\underset{\mathscr{G}}{\stackrel{x}{E}}$ & $\begin{array}{l}0 \\
0 \\
0 \\
0 \\
0 \\
0 \\
0 \\
0\end{array}$ & 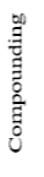 & $\frac{\stackrel{0}{\Xi}}{\frac{\tilde{g}}{\tilde{g}}}$ & $\frac{\stackrel{b}{\Xi}}{\stackrel{\vec{\partial}}{\Xi}}$ & 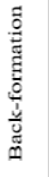 & 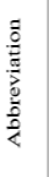 & 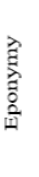 & 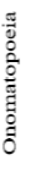 & 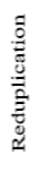 & 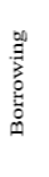 & 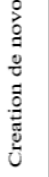 & 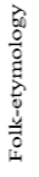 \\
\hline $\mathrm{B}_{7} \mathrm{Y}_{\mathrm{No}}$ & 35 & 87 & 16 & 70 & 0 & 3 & 1 & 0 & 7 & 2 & 1 & 114 & 0 & 0 \\
\hline In 5 & 10.4 & 25.9 & 4.8 & 20.8 & 0.0 & 0.9 & 0.3 & 0.0 & 2.1 & 0.6 & 0.3 & 33.9 & 0.0 & 0.0 \\
\hline
\end{tabular}

The second most productive method is suffixation by forming new words through suffixes such as badgering, ballonery, centrifugally, coxcombality, cryptogamic, hulky, imperialize, jokish, neologist, quizzical, reprobative, revolvency, servitorship, spoutless, theorism, and wigsby. The next method that English lexicon based on is compounding 70 entities, combining a word to another (as brushman, nipcheese, and sea-bath), a combining form to a word (as grandpa), a word to a combining form (as balloonomania), and a combining form to another (as novemfid).

Another approach to word formation is prefixation, with 35 entities, such as belittle, biternate, disintegrity, inattentive, obovate, re-edit, semi-palmate, subvariety, and unimpeachable. In addition, conversion happened 16 times from noun to verb (doss, hump, and prong), verb to noun (gamble, rut, and spank), verb to adjective (emarginated), and noun to adjective (nuts).

For the lesser frequent/productive methods, there were 7 eponyms (such as Constantia), 3 clipped words (as chit from chitty), 2 onomatopoeic words (as flab), 1 back-formation (rust from rusty), and 1 reduplication (goody-goody). However, there was no record for the other categories.

Table 2: methods of lexical enrichment in English in 1885, by number and in percentage 


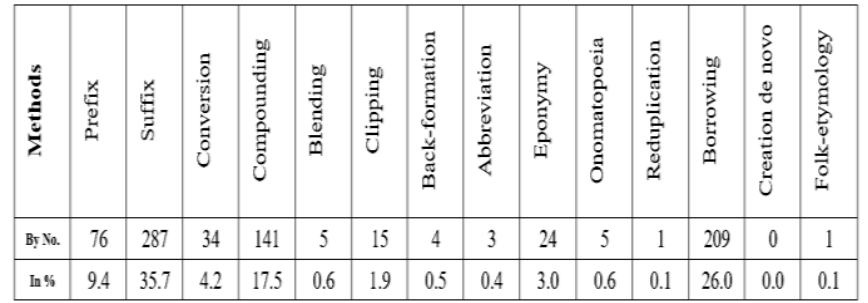

As noted above, a bigger number of coinages enriched English lexicon in 1885, which are 805 apart from the uncounted ones. As seen in Table 2, the most frequently used method is suffixation with 287 entities (35.7\%), such as acetylate, algebraicize, Americanesque, baglet, bankster, borrowee, cameldom, championage, disbursable, geomalism, horniness, maltate, maturish, specificize, spiderling, tabulator, and weirdsome.

By loaning from more than 30 languages, borrowing comes second with 209 entities, such as adenine (German), bandar (Hindi), bigos (Polish), charoset (Hebrew), conus (Latin), coperta (Italian), corella (Wiradhuri), dyslexia (French), hale (Hawaiian), hijab (Arabic), ilmoran (Masai), jnani (Sanskrit), Kamba (Bantu), kaza (Turkish), lactoglobulin (Danish), lakatoi (Papuan), levada (Portuguese), mandor (Malay), Narodnik (Russian), Nestilingmiut (Western Canadian Inuit), Nimpkish (Kwakiutl), parakeelya (Guyani), pasillo (Spanish), stolkjaerre (Norwegian), taclobo (a language of Philippines), tagma (Greek), Tamashek (Berber), tansu (Japanese), Taranchi (Jagatai), Tet (Vietnamese), ushabti (Egyptian), and witloof (Dutch).

The other method English enriched its lexicon is compounding, with 141 entities, by combining two words (such as bustline and cocksucker), a combining form and a word (as acetocarmine and hydrotherapeutic), a word and a combining form (as brickscape and dichoptic), and two combining forms (as aerophilous and zoophile). Relatively, another productive method was prefixation, attaching 76 prefixes to already existed words such as amphi- (in amphiaster), an- (anaerobiotic), circum- (circumcircle), de- (deprint), dys(dysmenorrhagia), epi- (epicuticle), hemi- (hemichordate), in- (inassimilation), mis- (miskick), off- (offprint), out(outscore), post- (postjudiced), pro- (progamous), re(rebid), sub- (subculture), under- (undertint), and up(upwell).

In 1885, there has been a conversion with 34 entities, such as bike, nursery, and telepath (noun to verb), balter, leave, and replot (verb to noun), housebroken and jack (verb to adjective), made-to-measure (noun to adjective), and multiplex (adjective to verb).

Also, English enriched its lexicon with 24 eponyms (such as Addisonian, Bismarck, Haarlem, Mason, and Pelton), 15 clipped words (as agar, crypto, and talkee), 5 blended words (as electret, Insinuendo, and museology), 5 onomatopoeias (as hallali, pleep, and yeow), 4 backformed words (as crust-hunt and mantle-make), 3 abbreviated ones (as OUDS, Nd, and Pr), 1 reduplication (yum-yum), and 1 folk-etymology (berceaunette).

Comparing to both previously mentioned years, 1985 has made smaller growth to the English lexicon with 187 entities. By excluding 26 of them for the reasons mentioned above, 56 entities $(34.8 \%)$ belonged to compounding, such as offshore (word + word), multibuy (combining form + word), footballene (word + combining form), and ovicide (combining form + combining form). Suffixation comes next with 34 entities, such as conspiracism, garmento, geekdom, maltiness, metabolon, perchery, presidentiable, Ramboesque, stripped, tanky, and tuneage.

Table 3: methods of lexical enrichment in English in 1985, by number and in percentage

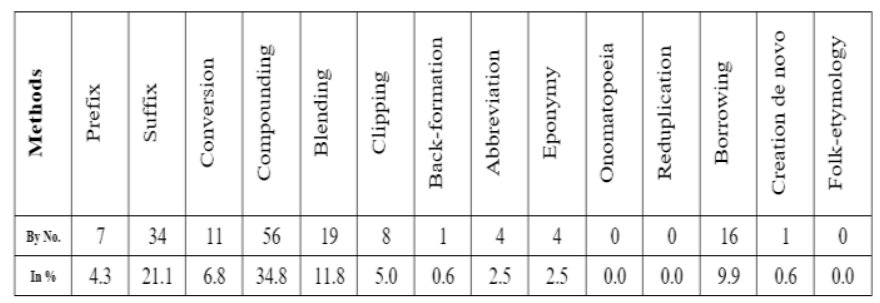

Dissimilar to 1785 and 1885, blending appears to be frequent with 19 entities, which makes $11.8 \%$ of the total lexical enrichment in 1985, as illustrated in Table 
3. The blended examples are am-dram, boxercise, hoolivan, Japanimation, monergy, rapso, snarfle, and tankini. Borrowing appears to be less frequent than the previously mentioned years with 16 entities. They are borrowed from Afrikaans (potjie), Arabic (intifada), French (Négrette), Hebrew (Krav Maga), Italian (guido), Japanese (kaizen), Latin (oviraptorosaur), south American Spanish (inti), and Vietnamese (banh mi). Conversion seems to have occurred 11 times only from noun to verb (such as focus-group and snowboard) and verb to noun (as crash-and-burn and mosh).

Comparing to the other two years, the use of the clipping method increased and made 5\% of the 1985 lexicon with 8 words, such as dexter (from poindexter), hox (from homeobex), and sim (from simulation). With closer number, prefixation comes next with 7 entities as off-guard, overramped, post-truth, and unattributively. Abbreviation occurred 4 times as BOGOF and WIMP, so did eponymy as benji and Rambo. There was 1 creation de novo for Semtex, and so was backformation for electroporate.

By comparing the three years in percentages, Figure 2 shows that suffixation and compounding played a significant role in lexical enrichment in English. Suffixation introduced $25.9 \%$ in $1785,35.7 \%$ in 1885 , and $21.1 \%$ in 1985 , compounding made $20.8 \%, 17.5 \%$, and $34.8 \%$ in 1785,1885 , and 1985 respectively.

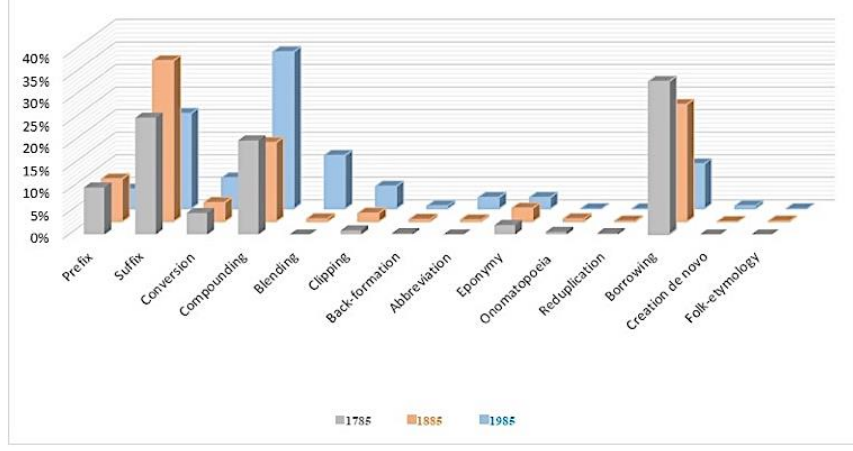

Figure 2: methods of lexical enrichment in English in 1785, 1885 , and 1985 in percentage

Some methods appeared to be frequent/productive but their percentages declined from 1785 to 1985 such as prefixation and borrowing. Prefixation dropped from $10.4 \%$ to $4.3 \%$, and borrowing from $33.9 \%$ to $9.9 \%$. Contrariwise, methods such as blending and clipping inclined, from $0.0 \%$ to $11.8 \%$ and $0.9 \%$ to 5.0 $\%$ respectively. The remained methods appeared to be evenly less in their frequency/productivity.

\section{Conclusions}

The aim of this study was to analyse different methods of lexical enrichment and their frequency/productivity in English in different periods namely 1785, 1885, and 1985. In light of morphology, three different categories have been shown: regular word-formation, new word-creation, and foreign. Then each category has been classified into different methods.

After having collected data for each year based on OED, there are some words whose etymologies are not clear to trace, introduced by mixed methods, and some others are miscategorised by OED. Therefore, in light of the given argument, the data are calculated based on etymologically linguistic evidence.

It has been found that the methods vary in enriching English vocabulary. While, suffixes and compounding are productive in all the three years, some other methods are infrequently used such as back-formation, eponymy, onomatopoeia, reduplication, creation de novo, and folk-etymology. The rest seem to decline as prefixes and borrowing or to incline such as blending and clipping.

\section{References}

1. Bauer, L. (1983). English word-formation. Cambridge University Press.

2. Bauer, L. (2001). Morphological Productivity. Cambridge: Cambridge University Press.

3. Bauer, L. (2006). 21 Compounds and Minor Wordformation Types. The handbook of English linguistics, 483 506.

4. Brinton, L. J. (2000). The structure of modern English: A linguistic introduction. John Benjamins Publishing. 
5. Coleman, J., \& Kay, C. J. (Eds.). (2000). Lexicology, semantics and lexicography: selected papers from the Fourth GL Brook Symposium, Manchester, August 1998 (Vol. 194). John Benjamins Publishing.

6. corella. (2019). In Merriam-Webster.com. Retrieved December 12, 2019, from https://www.merriamwebster.com/dictionary/corella

7. Cutler, A. (1980). Productivity in word formation. In The Sixteenth Regional Meeting, Chicago Linguistic Society (pp. 45-51). CLS.

8. Dressler, W. U., \& Ladányi, M. (2000). Productivity in word formation (WF): a morphological approach. Acta Linguistica Hungarica, 47(1-4), 103-145.

9. Dixon, R. M., Moore, B., Ramson, W. S., \& Thomas, M. (2006). Australian Aboriginal words in English: their origin and meaning. Oxford University Press.

10. Fernández-Domínguez, J. (2010). Productivity vs. lexicalization: frequency-based hypotheses on wordformation. Poznań Studies in Contemporary Linguistics, 46(2), 193-219.

11. Good, M. (2012) New words and dictionary making. [Lecture to lexical innovation Year 3, Newcastle Upon Tyne University] 22 November.

12. Grange, B., \& Bloom, D. A. (2000). Acronyms, abbreviations and initialisms. BJU International 86: 1-6.

13. Grose, F. (1931). A classical dictionary of the vulgar tongue. Beard Books.

14. Hacken, P. T., \& Panocová, R. (2013). The use of corpora in word formation research. Corela. Cognition, représentation, langage, (HS-13).

15. Harley, H. (2006). English Words: A Linguistic Introduction. Oxford: Blackwell.

16. Katamba, F. (1994). English Words. London and New York.

17. Kelly, M. (1998). To "brunch" or to "brench": Some aspects of blend structure. Linguistics 3: 579-590.

18. Kiparsky, P. (1982). Word-formation and the lexicon. Mid-America Linguistics Conference.

19. McAtee, W. L. (1951). Folk etymology in North American bird names. American Speech, 26(2), 90-95.

20. McMahon, A. M. (1994). Understanding language change. Cambridge University Press.

21. Michel, S. (2015). Word-formation and folk etymology. International handbook of the languages of Europe, 2, 1002-1020.

22. Minkova, D., \& Stockwell, R. (2009). English Words: History and Structure. $2^{\text {nd }}$ ed. Cambridge: Cambridge University Press.

23. Montero-Fleta, B. (2013). Cross-linguistic investigation of Greek and Latin prefixes: Spanish and English contrastively. Onomázein, (27), 269-285.

24. Moore, M. (2014). On buses and burgers: In defense of folk etymologies. SHAANAN, COLLEGE ANNUAL, Volume 20: E17-E22.

25. Nadarajan, S. (2006). A crosslinguistic study of reduplication. Arizona Working Papers in SLAT 13: 39-53.

26. OED: Oxford English Dictionary, http://www.oed.com/ [last accessed 10 $10^{\text {th }}$ November, 2019]

27. Palmer, A. S. (1882). Folk-etymology: A dictionary of verbal corruptions or words perverted in form or meaning, by false derivation or mistaken analogy. G. Bell and sons.

28. Plag, I. (2006). Productivity. The Handbook of English Linguistics, ed. by Bas Aarts and April McMahon, 537556.

29. Plag, I. (2018). Word-formation in English. Cambridge University Press.

30. Rastall, P. (2004). Playful English: kinds of reduplication. English Today, 20(4), 38-41.

31. Ratih, E., \& Gusdian, R. I. (2018). WORD FORMATION PROCESSES IN ENGLISH NEW WORDS OF OXFORD ENGLISH DICTIONARY (OED) ONLINE. Celtic: A Journal of Culture, English Language Teaching, Literature, $\mathcal{E}$ Linguistics, 5(2), 24-35.

32. Sayers, W. (2012). Challenges for English Etymology in the Twenty-First Century, with Illustrations. Studia Neophilologica, 84(1), 1-25.

33. Štekauer, P. (1998). An onomasiological theory of English word-formation. John Benjamins.

34. Štekauer, P., \& Lieber, R. (Eds.). (2006). Handbook of word-formation (Vol. 64). Springer Science \& Business Media.

35. Tokar, A. (2012). Introduction to English morphology. Peter Lang.

36. Wright, J. (1898). The English Dialect Dictionary. Vol. 1 (AC), Oxford, Henry Frowde. 